\title{
Progesterone Negatively Regulates BCRP in Progesterone Receptor-Positive Human Breast Cancer Cells
}

\author{
Xiaojuan Wu $u^{\mathrm{a}, \mathrm{c}}$ Xiaofang Zhang, ${ }^{\mathrm{a}, \mathrm{c}}$ Limin Sun ${ }^{\mathrm{b}}$ Hui Zhang ${ }^{\mathrm{a}}$ Li Li $^{\mathrm{a}}$ Xiao Wang \\ Weiwei $\mathrm{Li}^{\mathrm{a}}$ Peng Su${ }^{\mathrm{a}}$ Jing Hu${ }^{\mathrm{a}}$ Peng Gao ${ }^{\mathrm{a}}$ Gengyin Zhou \\ ${ }^{a}$ Department of Pathology, School of Medicine, Shandong University, Shandong, China; ${ }^{b}$ Department \\ of Orthopedics, Shandong Jiaotong Hospital, Shandong, China; 'Xiaojuan Wu and Xiaofang Zhang \\ contributed equally to this work
}

\section{Key Words}

Breast cancer resistance protein - Transcriptional regulation • Progesterone $\cdot$ RU-486 • Breast cancer cells

\begin{abstract}
Background/Aims: Breast cancer resistance protein (BCRP) plays a crucial role in multidrug resistance (MDR). Previous studies have shown that steroid hormones, like progesterone (PROG), regulate BCRP expression. The presence of a progesterone response element (PRE) in the $B C R P$ promoter, suggests that PROG may regulate transcription of BCRP. Methods: To investigate the role of PROG in the regulation of BCRP expression, two constructs encoding full-length $B C R P$ driven by either an endogenous PRE promoter or a constitutive CMV promoter, were transfected into T47D cells that express the progesterone receptor (PR) or into PR-negative MDA-MB-231 cells. Results: After treatment with PROG, qPCR and Western blotting analyses indicated that BCRP mRNA and BCRP protein levels were significantly reduced in a dose-dependent manner in PR-positive cells, but PROG had no significant effect on BCRP levels in the PR-negative cells. The effect observed in PR-positive cells was reversed by co-treatment with RU-486, a specific PROG inhibitor. Cytometric analysis confirmed that BCRP-mediated drug efflux was inhibited and chemosensitivity to mitoxantrone was markedly increased by PROG treatment. Conclusion: These results suggest that PROG reverses BCRPmediated MDR by down-regulating BCRP expression in breast cancer cells by affecting transcription from the PRE-containing BCRP promoter. Our studies suggest that breast cancer patients with BCRP-mediated MDR may be successfully treated with PROG.
\end{abstract}




\section{Cellular Physiology and Biochemistry}

Cell Physiol Biochem 2013;32:344-354

DOI: $10.1159 / 000354442$

(14, 2013

Wu et al.: Progesterone Regulates BCRP via Progesterone Receptor

\section{Introduction}

Breast cancer is the most prevalent type of cancer documented in women. Multidrug resistance (MDR) is the greatest obstacle preventing effective chemotherapy treatment in these patients. One outcome of MDR involves the expulsion of a wide range of structurally and functionally unrelated drugs being pumped out of cancer cells by ATP-binding cassette (ABC) transporter proteins [1]. Breast cancer resistance protein (BCRP) is an ABC transporter protein that was first identified in human breast cancer cells those were grown in the presence of adriamycin and vincristine. BCRP is expressed at high levels in cells isolated from various tumors[2-4]. BCRP mediates resistance to adjuvant chemotherapeutic agents such as mitoxantrone, topotecan, and SN-38 [5-8], presumably by acting as an efflux pump to inhibit intracellular accumulation and reduce cytotoxic effects [9]. Although much has been uncovered regarding the molecular roles of BCRP, a better understanding of the mechanisms regulating BCRP expression is necessary to guide development of strategies to reverse MDR in breast cancer patients.

Steroid hormones like estrogen and progesterone (PROG) regulate BCRP expression via receptor-mediated pathways. One such example is that of the estrogen receptor (ER), which regulates BCRP expression in breast cancer cells via ER elements (ERE) in the BCRP promoter. Progesterone receptor (PR) is also a steroid hormone receptor and its expression is tightly regulated by estrogen [10], as such PR levels should be reduced in ER-negative breast cancer cells. However, this is not the case given that certain ER-negative breast cancer types have high levels of PR expression. Our previous studies in isolated cells revealed that BCRP expression is down-regulated upon treatment with toremifene. Toremifene reverses BCRP-mediated MDR through TOR-ER complexes that bind to the ERE in the BCRP promoter and inhibit the transcription of $B C R P$ [11]. The progesterone response element (PRE), which is a similar regulatory element present in the $B C R P$ promoter, was also recently identified [12]. Little is known about the role of this novel element in the BCRP-mediated MDR pathway in breast cancer cells.

In PR transfected PR- or ER-negative breast cancer cells, DNA synthesis and cell proliferation are markedly inhibited by PROG treatment [13], suggesting that PROG may have a role in cancer growth inhibition. In support of this, megestrol acetate (MA), a synthetic form of PROG that specifically binds to the PR, has been successfully used to treat advanced breast cancer, endometrial cancer, and prostate cancer. Treatment of breast cancer cells in vitro with MA reverses resistance to adriamycin and vincristine [14-16]. However, the underlying mechanisms are not understood.

In this study we over-expressed BCRP in PR-positive T47D and PR-negative MDAMB-231 breast cancer cells and characterized the role of the PRE in the BCRP promoter in BCRP-mediated MDR. Our results provide new insights into PROG-mediated regulation of BCRP expression in human breast cancers.

\section{Materials and Methods}

Chemicals, reagents, and antibodies

PROG, mifepristone (RU-486), mitoxantrone, dimethyl sulfoxide (DMSO), and 3-(4,5-dimethylthiazol2-yl)-2,5-diphenyltetrazolium bromide (MTT) were purchased from Sigma-Aldrich (St. Louis, MO, USA). RPMI-1640 medium with L-glutamine and without phenol red or fetal bovine serum (FBS) were purchased from Invitrogen (Carlsbad, CA, USA). The anti-BCRP antibody was purchased from Abcam (Cambridge, MA, USA), and anti-PR antibody was from ProMab (Richmond, CA, USA). The anti- $\beta$-actin antibody was from Beyotime (Haimen, Jiangsu, China).

Cells and cell culture

Human breast adenocarcinoma cell lines, T47D and MDA-MB-231, were obtained from the United States National Cancer Institute. Cells were maintained in RPMI-1640 medium supplemented with 


\section{Cellular Physiology and Biochemistry}

Cell Physiol Biochem 2013;32:344-354

\begin{tabular}{l|l}
\hline DOI: $10.1159 / 000354442$ & (C) 2013 S. Karger AG, Basel
\end{tabular}

Wu et al.: Progesterone Regulates BCRP via Progesterone Receptor

$10 \%(\mathrm{v} / \mathrm{v})$ FBS, $100 \mathrm{U} / \mathrm{mL}$ penicillin, and $100 \mathrm{mg} / \mathrm{L}$ streptomycin in a humidified atmosphere with $5 \% \mathrm{CO}_{2}$ at $37^{\circ} \mathrm{C}$.

Immunocytochemical analysis of PR in T47D and MDA-MB-231 cells

Cells were seeded on a glass slide in 24-well plates at about 5,000 cells/well. After $48 \mathrm{hrs,} \mathrm{cells}$ were fixed with methanol for 2 hrs. After permeabilization and blocking, cells were incubated with antiPR antibody (dilution 1:200) overnight at $4{ }^{\circ} \mathrm{C}$. The slides were then probed with poly-HRP conjugated to secondary antibody for 25 min and visualized using DAB (PV-9000, ZSGB-Bio, Beijing, China).

\section{RNA extraction, PCR amplification, and plasmid construction}

Total RNA was extracted from cell lines using Trizol reagent (TaKaRa, Kyoto, Japan). cDNA synthesis and qualitative real-time PCR (qPCR) reactions were performed as described previously[17]. The primers used to amplify the human BCRP promoter region were 5'-GCC AGT GAC GGC GAC CAA-3' (sense) and 5'-AGC GCT GAC ACG AAC TTC CTA A-3' (antisense). Primers used to amplify the wild-type human BCRP CDNA were 5'-GCT GCG GCC GCG AAC TGG GTA GGA TTT AGG-3' (sense) and 5'-CCC GCG GCC GCT GAA AGA ACC CAA GAC AT-3' (antisense).

The amplified full-length $B C R P$ cDNA was inserted into pEGFP-C1 vector behind a CMV promoter (Invitrogen, Carlsbad, CA, USA). This created the vector we refer to as C-BCRP for expression of BCRP under control of the CMV promoter. ApaI/BamHI digestion was used to construct pEGFP/C-BCRP. To generate the pEGFP/P-BCRP construct, the BCRP promoter cDNA was first cloned into pMD20-T (TaKaRa, Kyoto, Japan) and then sub-cloned into pEGFP/C-BCRP with SnaBI/NheI digestion to destroy the CMV promoter. The construct, named P-BCRP, allowed expression of BCRP under control of the wild-type BCRP promoter. All constructs were sequenced.

Cell transfection, stable cell line establishment, and drug treatment

For each construct, $8 \mu \mathrm{l}$ of Lipofectamine (Invitrogen, Carlsbad, CA, USA) and $4 \mu \mathrm{g}$ of construct were diluted into $250 \mu \mathrm{l}$ of RPMI-1640 without serum. After incubating for 5-min at room temperature, samples were mixed and incubated for an additional $25 \mathrm{~min}$. Cells were initially seeded in 6-well plates at $1 \times 10^{6}$ cells per well. After $12 \mathrm{hrs}$, cells were washed three times with RPMI-1640 and then the mixture of construct and Lipofectamine was added. Six hours after transfection, the culture medium was changed to complete RPMI-1640 with 10\% FBS.

For stable cell line establishment, transfected cells were switched to fresh medium and selected by growth in complete medium containing $500 \mu \mathrm{g} / \mathrm{ml}$ geneticin (G418; Invitrogen, Carlsbad, CA, USA) for 4 weeks. RT-PCR and Western blotting were used to confirm stable expression of BCRP. Cells stably expressing BCRP were maintained in RPMI-1640 with $10 \%$ FBS for at least 24 hrs before PROG treatment. PROG was added to the medium at final concentrations of $0.001,0.1$, or $10 \mu \mathrm{M}$ and cells were incubated for 48 or 72 hrs. For treatment with both RU-486 and PROG, cells were first incubated with $100 \mu \mathrm{M}$ MRU-486 for 24 hrs. Culture medium was replaced with fresh medium containing $10 \mu \mathrm{M}$ PROG and $100 \mu \mathrm{M}$ RU-486, and cells were incubated for another $48 \mathrm{hrs}$. Cells were then harvested for mRNA and Western blotting analyses.

Quantitative real-time RT-PCR

Total RNA was isolated from cell lines using Trizol reagent (TaKaRa, Kyoto, Japan) according to the manufacturer's instructions. The first-strand cDNA was synthesized from $0.5 \mu \mathrm{g}$ total RNA using ReverTra Ace qPCR RT Kit (TOYOBO, ShangHai, China). The BCRP mRNA was amplified with SYBR® Green Realtime PCR Master Mix (TOYOBO, ShangHai, China) as previously described [18]. The sense and antisense primers for amplification of BCRP cDNA were 5'-TGGCTGTCATGGCTTCAGTA-3' and 5'-GCCACGTGATTCTTCCACAA-3', respectively. Sense and antisense primers for amplification of $\beta$-actin cDNA were 5'-ACCCCCACTGAAAAAGATGA-3' and 5'-ATCTTCAAACCTCCATGATG-3', respectively. The mRNA levels of each gene evaluated were normalized to levels of $\beta$-actin according to the formula: $\Delta \mathrm{C}_{\mathrm{T}}=\mathrm{C}_{\mathrm{T}}(b c r p)$ $\mathrm{C}_{\mathrm{T}}\left(\beta\right.$-actin) and $\Delta \Delta \mathrm{C}_{\mathrm{T}}=\Delta \mathrm{C}_{\mathrm{T}}$ (test group) $-\Delta \mathrm{C}_{\mathrm{T}}$ (control group). Relative $B C R P$ mRNA levels are expressed as $2^{-\Delta \Delta C \mathrm{~T}}$

Protein extraction and Western blotting

Proteins were extracted by first incubating cells with lysis buffer (50 mM Tris-HCl (pH 8.0), $150 \mathrm{mM}$ $\mathrm{NaCl}, 0.5 \%$ Triton X-100, 2 mM EDTA (pH 8.0), 5 mM DTT, $0.2 \mathrm{mM}$ phenylmethylsulfonyl fluoride, and 10 


\section{Cellular Physiology and Biochemistry}

Cell Physiol Biochem 2013;32:344-354

DOI: $10.1159 / 000354442$

(C) 2013 S. Karger AG, Basel

www.karger.com/cpb

Wu et al.: Progesterone Regulates BCRP via Progesterone Receptor

$\mu \mathrm{g} / \mathrm{ml}$ aprotinin) for $25 \mathrm{~min}$ on ice [19]. Samples were then centrifuged at $12,000 \mathrm{~g}$ for $15 \mathrm{~min}$ at $4{ }^{\circ} \mathrm{C}$ to remove cell debris. The extracted proteins were boiled at $100{ }^{\circ} \mathrm{C}$ for $5 \mathrm{~min}$ and then fractionated on SDSPAGE. Proteins were transferred from the gel to a polyvinylidene difluoride membrane (Millipore, Billerica, MA, USA). After blocking with 5\% fat-free milk in TBS at room temperature for 2 hrs, the membrane was incubated with antibodies against human BCRP or human $\beta$-actin overnight at $4{ }^{\circ} \mathrm{C}$. The membrane was washed three times with TBST at room temperature and then incubated with a horseradish peroxidase (HRP)-conjugated goat anti-mouse IgG secondary antibody at $37^{\circ} \mathrm{C}$ for $1 \mathrm{hr}$. Finally, the membranes were visualized using an enhanced chemiluminescence kit (Millipore, Billerica, MA, USA) according to the manufacturer's instruction.

Flow cytometric analysis

To detect transport mediated by BCRP, mitoxantrone was used as a fluorescence tracer. After trypsinization, cells $\left(1 \times 10^{6}\right)$ were re-suspended in complete RPMI-1640 with $10 \%$ FBS as a control, or re-suspended and incubated in complete medium containing $20 \mu \mathrm{M}$ mitoxantrone at $37{ }^{\circ} \mathrm{C}$ for $30 \mathrm{~min}$ in $5 \% \mathrm{CO}_{2}$ and then allowed to efflux for $1 \mathrm{hr}$. Cells were then washed with ice-cold PBS. A FACSCalibur flow cytometer (BD Biosciences, San Jose, CA, USA) equipped with a $635 \mathrm{~nm}$ red diode laser and $670 \mathrm{~nm}$ band pass filter was used to detect mitoxantrone fluorescence.

\section{Cytotoxicity assay}

MTT assays were performed as previously reported [20]. Briefly, $1 \times 10^{4}$ cells in $0.1 \mathrm{ml}$ RPMI-1640 supplemented with $10 \%$ FBS were plated each well of a 96-well plate and maintained at $37{ }^{\circ} \mathrm{C}$ for $24 \mathrm{hrs}$. Cells were first treated with RU-486 $(100 \mu \mathrm{M})$ for $24 \mathrm{hrs}$, and then incubated with fresh medium containing PROG $(10 \mu \mathrm{M})$ for $72 \mathrm{hrs}$. Mitoxantrone was then added at indicated concentrations, and cells were incubated for another $48 \mathrm{hrs}$. Cells were then stained with $20 \mu \mathrm{l}$ of sterile MTT per well ( $5 \mathrm{mg} / \mathrm{ml}$ ) for $4 \mathrm{hrs}$ at $37^{\circ} \mathrm{C}$. Subsequently, culture medium was discarded and $150 \mu \mathrm{l}$ of DMSO was added, and samples were mixed for $10 \mathrm{~min}$. Absorbance at $490 \mathrm{~nm}$ was measured using an automatic multi-well spectrophotometer (Bio-Rad, Hercules, CA, USA). The relative drug resistance was determined by comparing the $\mathrm{IC}_{50}($ drug concentration causing $50 \%$ inhibition of cell growth) with growth inhibition curves.

\section{Statistical analyses}

Data analysis was performed with SPSS software version 18.0. Results are presented as means \pm SD. Comparisons between groups were made using one-way analysis of variance (ANOVA) followed by Student's paired $t$-test to determine significance. Values of $P<0.05$ were considered significant.

\section{Results}

Expression of PR by T47D and MDA-MB-231 cells

The expression of PR was detected by immunocytochemistry in the two breast cancer cell lines in this study. Nuclei of T47D cells were positive for PR, and nuclei were negative for PR in MDA-MD-231 cells (Fig. 1).

\section{PROG treatment decreased BCRP mRNA transcription driven by a PRE-containing} promoter

To examine whether PROG regulates $B C R P$ expression in a PRE-dependent manner, we evaluated BCRP mRNA levels in PROG-treated PR-positive T47D cells and PR-negative MDA-MB-231cells that stably express BCRP driven either by a CMV promoter (C-BCRP) or the wild-type promoter containing the PRE sequence (P-PCRP). PROG treatment decreased BCRP mRNA levels in a dose-dependent manner in T47D cells that stably expressed P-BCRP (Fig. 2A). PROG had no significant effect on levels of BCRP mRNA in cells in which expression was driven by the CMV promoter (Fig. 2B). The effect of $10 \mu \mathrm{M}$ PROG was almost completely abolished by co-treatment of cells with $100 \mu \mathrm{M}$ RU-486 (Fig. 2C, $P<0.01$ ). PROG plus RU-486 had no significant effect on BCRP mRNA levels in C-BCRP expressing T47D cells (Fig. 2D). No significant changes were detected following PROG treatment in MDA-MB-231 cells stably 


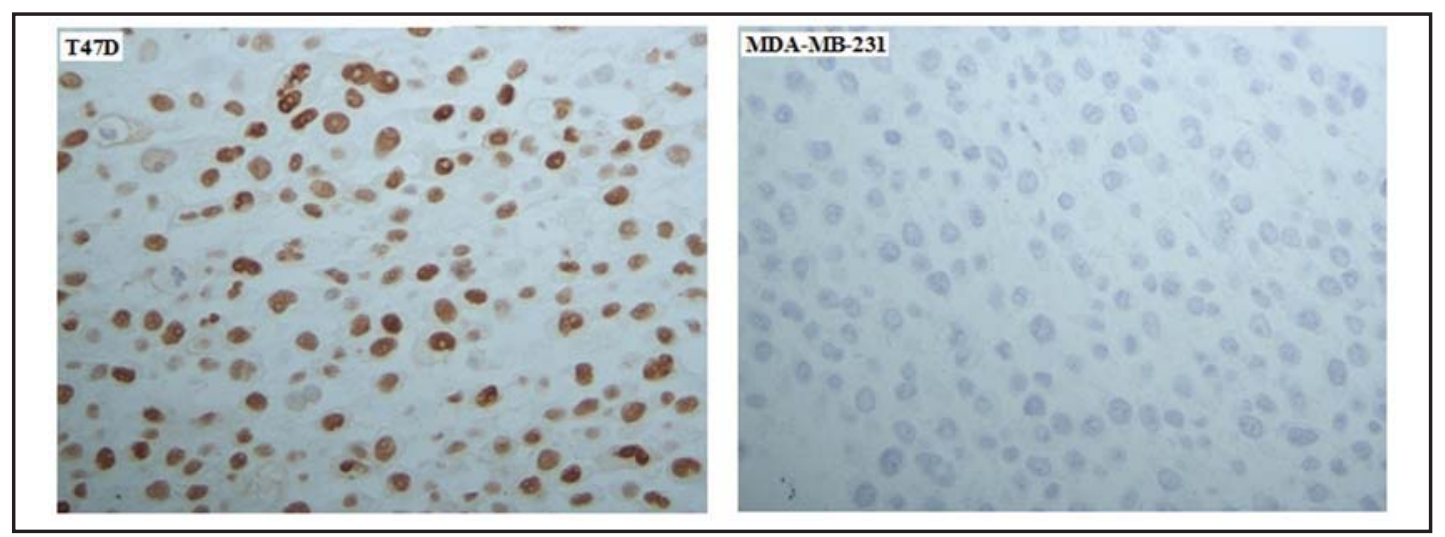

Fig. 1. T47D cells express the progesterone receptor. PR was detected by immunocytochemistry in nuclei of T47D cells (left panel) but not MDA-MB-231cells (right panel). Magnification 400×.

Fig. 2. $P R O G$ inhibited the expression of exogenous $B C R P$ mRNA from the PRE-driven promoter. (A and B) T47D cells expressing (A) P-BCRP or (B) C-BCRP were cultured in the presence of the indicated concentration of PROG for $48 \mathrm{hrs}$ or in $10 \mu \mathrm{M}$ PROG in the absence or presence of $100 \mu \mathrm{M}$ RU-486 for 48 hrs (C and D). T47D cells expressing (C) P-BCRP or (D) C-BCRP were cultured in the presence or absence of $10 \mu \mathrm{M}$ PROG in the absence or presence of $100 \mu \mathrm{M}$ RU-486 for $48 \mathrm{hrs}$. Total RNA was extracted and the relative $B C R P$ mRNA levels were determined by qPCR; BCRP levels were normalized to levels of $\beta$-actin. Data were from three independent experiments.

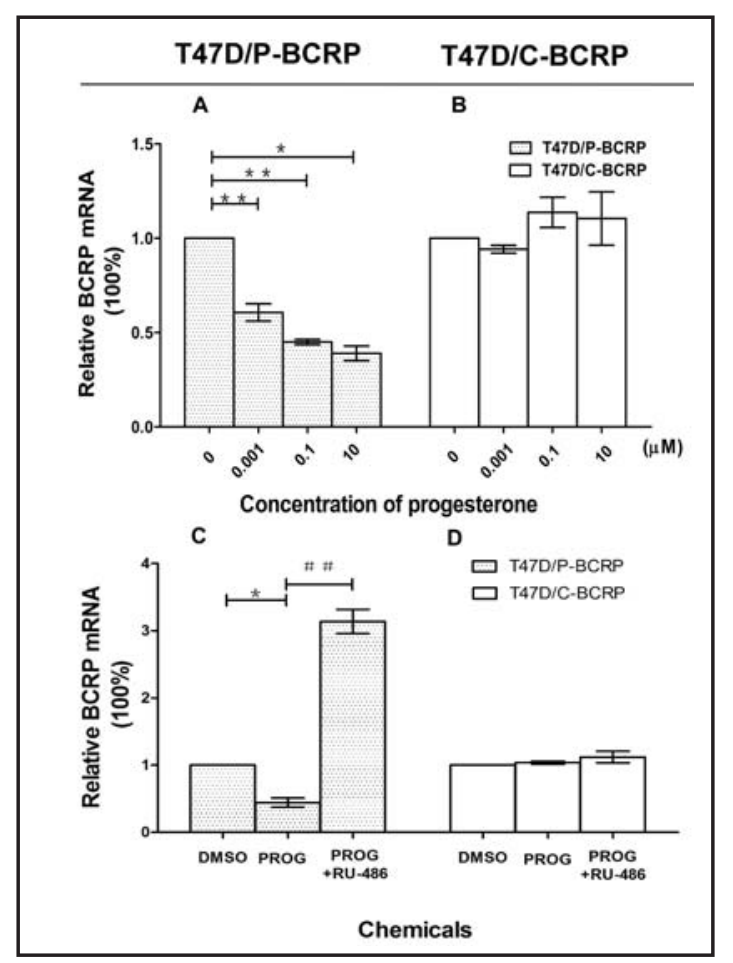

expressing either P-BCRP or C-BCRP (data not shown). These results indicate that PRE is necessary for PROG-induced $B C R P$ transcriptional activation.

\section{PROG treatment inhibited BCRP protein expression in PR-positive cells}

To further evaluate the effect of PROG on exogenous BCRP protein expression, we treated T47D cells expressing either P-BCRP or C-BCRP with various concentrations of PROG (from 0 to $10 \mu \mathrm{M}$ ) for $72 \mathrm{hrs}$. Proteins were then extracted for Western blotting analysis. In P-BCRP-expressing cells, PROG treatment inhibited BCRP expression in a dose-dependent manner $(P<0.01)$ (Fig. 3A). In cells containing the BCRP gene driven by the CMV promoter, treatment with $0.001 \mu \mathrm{M}$ or $0.01 \mu \mathrm{M}$ PROG induced a statistically significant increase in BCRP, but treatment with $10 \mu \mathrm{M}$ had little impact on BCRP protein levels (Fig. 3B). We then pre-treated cells stably transfected with P-BCRP with $100 \mu \mathrm{M}$ RU-486 prior to the addition of $10 \mu \mathrm{M}$ PROG. Under these conditions, BCRP protein levels increased compared to both control and PROG alone groups (Fig. 3C; $P<0.01$ ). In T47D/C-BCRP cells, both PROG alone and RU-486 combined with PROG induced expression of BCRP to levels significantly higher 


\section{Cellular Physiology and Biochemistry}

Cell Physiol Biochem 2013;32:344-354

DOI: 10.1159/000354442

Published online: August 14, 2013

C) 2013 S. Karger AG, Basel

www.karger.com/cpb

Wu et al.: Progesterone Regulates BCRP via Progesterone Receptor

Fig. 3. PROG treatment inhibited BCRP protein expression from the exogenous gene with the PREcontaining promoter. (A and B) Cells expressing BCRP from either (A) the P-BCRP construct or (B) the C-BCRP construct were treated with PROG at the indicated concentrations for $72 \mathrm{hrs}$, cells were harvested, and proteins were separated by SDS-PAGE followed by Western blotting with anti-BCRP antibody and anti- $\beta$-actin antibody. Densitometric analysis was then performed. (C and D) Cells expressing BCRP from either (C) the P-BCRP construct or (D) the C-BCRP construct were first treated with $100 \mu \mathrm{M}$ RU-486 for $24 \mathrm{hrs}$ and then $10 \mu \mathrm{M}$ PROG was added, and cells were incubated for $48 \mathrm{hrs}$ before harvest. Total proteins were subjected to SDS-PAGE followed by Western blotting with anti-BCRP antibody and anti- $\beta$-actin antibody. Densitometric analysis was then performed.

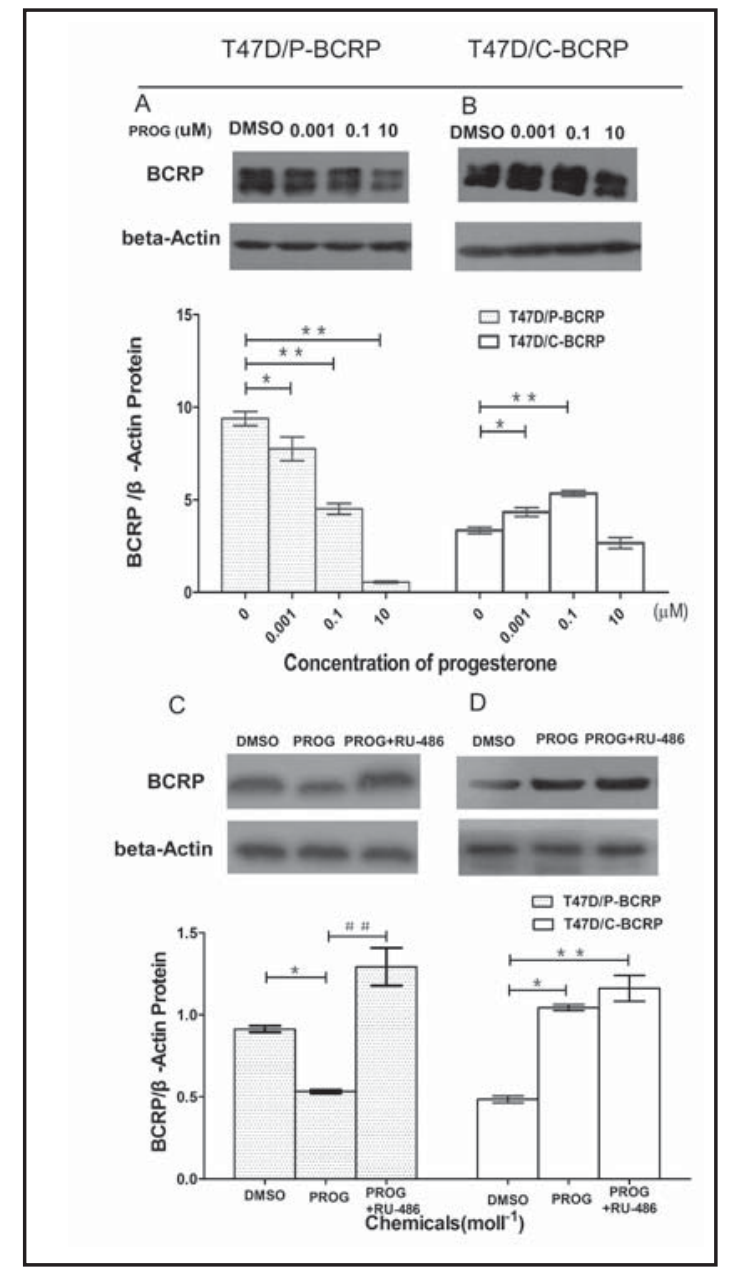

than those in the control cells (Fig. 3D; $P<0.05$ ). Western blotting for BCRP revealed two specific bands that likely resulted from different levels of glycosylation of BCRP. To obtain more objective results, the intensities of the two bands were combined in densitometry analyses. We conclude that the regulation of BCRP protein levels in the two cell lines resulted from differences in the promoters.

\section{PROG treatment suppressed BCRP-mediated drug efflux}

Mitoxantrone is a specific substrate of BCRP that can be used to measure BCRP transport activity. To investigate whether PROG treatment alters BCRP efflux activity, we used a previously described mitoxantrone efflux assay [21] to examine intercellular drug accumulation in T47D cells, in T47D cells that express BCRP under control of the PREcontaining promoter, and in T47D cells that express BCRP under control of the CMV promoter after treatment with $10 \mu \mathrm{M}$ PROG with or without $100 \mu \mathrm{M}$ RU-486. As shown in Figure 4, after PROG treatment, the fluorescence peak was shifted rightward in T47D/P-BCRP cells compared to negative control T47D cells indicating inhibition of mitoxantrone efflux. When the cells were treated with PROG and RU-486, the PROG-mediated efflux of mitoxantrone was greatly abrogated, suggesting that PROG inhibited the BCRP efflux activity and RU-486 reversed this effect. Interestingly, in T47D/C-BCRP cells, treatment with PROG resulted in a shift in the fluorescence peak to the left, which implied that efflux via BCRP was decreased, and this effect was not abolished by RU-486 treatment. The same phenomena were detected in both MDA-MB-231/P-BCRP and MDA-MB-231/C-BCRP cells (data not shown). 


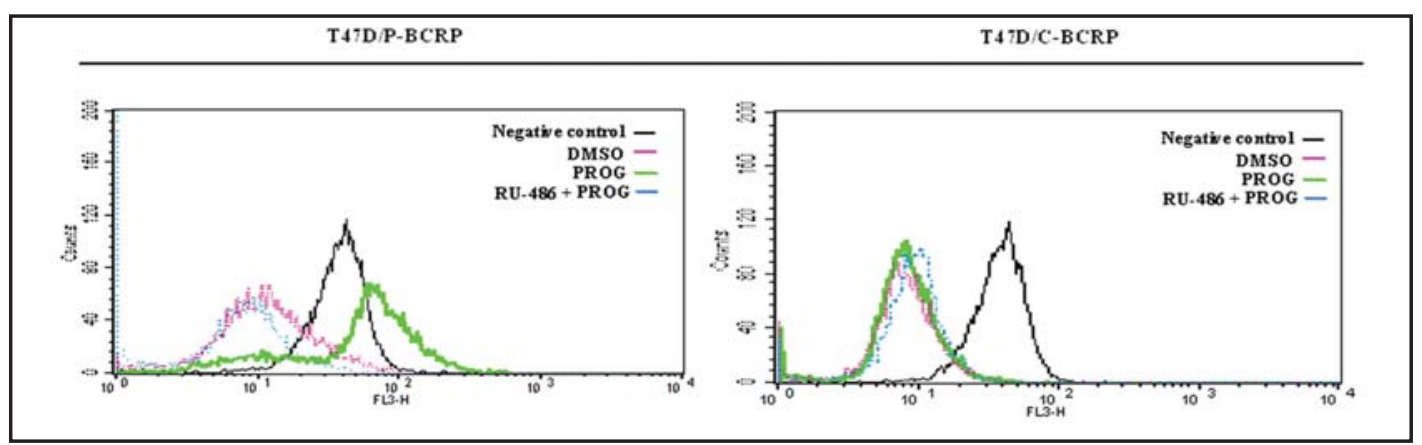

Fig. 4. PROG treatment suppressed BCRP-mediated drug efflux. Cells were incubated in 10 $\mu$ M PROG without or with $100 \mu \mathrm{M}$ RU-486 for $48 \mathrm{hrs}$. The intercellular levels of mitoxantrone were measured by fluorescence activated cell sorting. The black lines represented negative control cells, the pink lines represent DMSOtreated T47D/B-CRP cells, the green lines represent 10 $\mu \mathrm{M}$ PROG-treated cells, and the blue lines represent cells treated with $100 \mu \mathrm{M}$ RU-486 and with $10 \mu \mathrm{M}$ PROG. Data are means \pm SD values from triplicate determinations.

Fig. 5. PROG treatment enhanced sensitivity of BCRP-expressing cells to mitoxantrone. Cytotoxicity was assessed by MTT assay. Cells were seeded in 96well plates with $1 \times 10^{4}$ cells per well, then treated in with mitoxantrone at concentrations ranging from 0 to $100 \mu \mathrm{M}$ for $48 \mathrm{hrs}$. Data are presented as percentages relative to the control T47D cells. Data are means \pm SD values from three independent experiments.

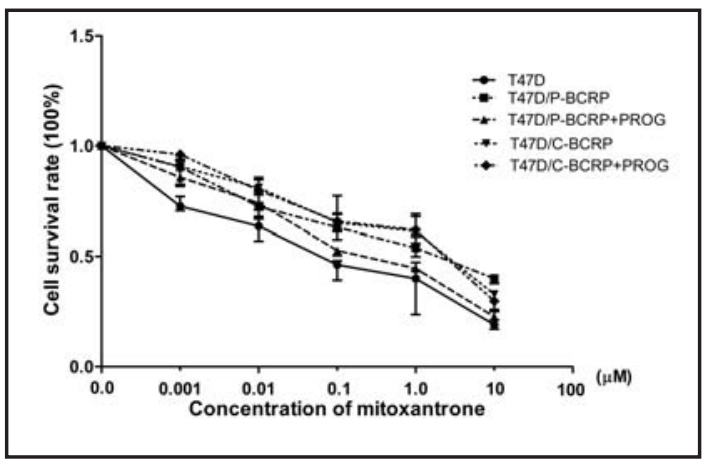

Table 1. $\mathrm{IC}_{50}$ values of mitoxantrone in each group $\mathrm{IC}_{50}$ is the drug concentration $(\mu \mathrm{M})$ indicating $50 \%$ inhibition of the cell growth. Value of RR (short for relative drug resistance) of the T47D cells was set as 1 . Results are represented as mean \pm SD from at least triplicate independent experiments. ${ }^{* *} P<0.01$ compared with T47D, ${ }^{\triangle} P<0.01$ compared with T47D/P-BCRP, T47D/CBCRP+PROG and T47D/C-BCRP.

\begin{tabular}{lcc}
\hline \multicolumn{1}{c}{ Group } & $\mathrm{IC}_{50}(\mu \mathrm{M})$ & $\mathrm{RR}$ \\
\hline T47D/P-BCRP+PROG & $0.26 \pm 0.03^{\Delta \triangle}$ & 4.63 \\
T47D/P-BCRP & $1.36 \pm 0.36^{\cdots}$ & 25.08 \\
& & \\
T47D/C-BCRP+PROG & $1.25 \pm 0.26^{\cdots}$ & 22.61 \\
& & \\
T47D/C-BCRP & $1.40 \pm 0.17^{\cdots}$ & 24.40 \\
& & \\
T47D & $0.06 \pm 0.02$ & 1 \\
\hline
\end{tabular}

PROG treatment enhanced chemosensitivity of BCRP-expressing cells

The observation that PROG inhibited BCRP-mediated drug efflux implies that PROG treatment may increase the sensitivity of cancer cells to chemotherapy (Fig. 5). To validate this hypothesis, we analyzed survival of T47D cells treated with mitoxantrone that stably express $B C R P$ under the control of the PRE-containing promoter and the CMV promoter. The $\mathrm{IC}_{50}$ values were $0.06( \pm 0.02) \mu \mathrm{M}$ in T47D cells, $1.36( \pm 0.36) \mu \mathrm{M}$ in T47D/P-BCRP cells, and $1.40( \pm 0.17) \mu \mathrm{M}$ in T47D/C-BCRP cells. Treatment of T47D/C-BCRP cells with PROG did not significantly change the $\mathrm{IC}_{50}$, which was $1.25( \pm 0.26) \mu \mathrm{M}$. In contrast, the $\mathrm{IC}_{50}$ in $\mathrm{T} 47 \mathrm{D} / \mathrm{P}$ BCRP cells treated with PROG decreased to $0.26( \pm 0.03) \mu \mathrm{M}$. Compared with T47D cells, the sensitivity of T47D/C-BCRP cells to mitoxantrone increased $\sim 24$ fold $(P<0.01)$. The sensitivity of T47D/P-BCRP cells was $\sim 25$ fold higher than that of the control cells $(P<0.01)$. After treatment with PROG, the sensitivity was $\sim 5$ fold higher than that of the control cells, 
an effect that did not reach statistical significant (Table 1). These results suggest that PRpositive cells that express BCRP under control of a promoter containing PRE are significantly chemosensitized upon treatment with PROG.

\section{Discussion}

BCRP was first identified in MCF-7/AdrVp human breast cancer cell lines [22, 23] and is over-expressed in placental syncytiotrophoblasts, canalicular membranes of the liver, small intestine epithelium, endothelial cells of microvessels, and mammary epithelial cells. The localization of BCRP in normal tissues suggests that it plays a protective role [24, 25]. BCRP is highly expressed in many types of tumors, and its efflux activity confers resistance to a variety of chemotherapeutic agents including mitoxantrone, topotecan, and anthracyclines $[26,27]$. BCRP expression reduces the efficacy of many cancer chemotherapeutics.

Nuclear receptors, especially ER, are important determinants of BCRP expression levels in tumor cells. Imai et al. reported that both estrogens and anti-estrogens restrain BCRPmediated drug resistance. Furthermore, they found that physiological levels of estradiol $\left(\mathrm{E}_{2}\right)$ reduce BCRP expression by a post-transcriptional mechanism in ER- $\alpha$ positive cells [28-30]. Our group reported that $17 \beta-\mathrm{E}_{2}$ regulates the level of $B C R P$ mRNA at the transcriptional level [11]. We found that down-regulation of $B C R P$ gene expression and the reversal of multi-drug resistance by tamoxifen are mediated by a novel transcriptional mechanism. Specifically, the TOR-ER complex binds to the ERE in the BCRP promoter and associates with components of the transcription machinery to inhibit transcription activation of $B C R P$ [31]. However, the effect of PR on the regulation of BCRP in breast cancer was not clear.

PR may be regulated by ER, and the presence of PR suggests that ER is not only present but also functional in various types of cancer cells [32]. However, about $10 \%$ of primary breast cancers are negative for ER but positive for PR. A recent retrospective analysis of the breast cancer patients treated with tamoxifen or with aromatase inhibitors showed that patients with $\mathrm{ER}^{+} / \mathrm{PR}^{+}$tumors are more likely to be hormone responsive, whereas patients with $\mathrm{ER}^{+} / \mathrm{PR}^{-}$tumors are less likely to benefit from tamoxifen therapy than those with $\mathrm{ER}^{-} /$ $\mathrm{PR}^{-}$tumors. Importantly, patients with $\mathrm{ER}^{-} / \mathrm{PR}^{+}$tumors had a poorer disease-free and overall survival compared with patients with $\mathrm{ER}^{+} / \mathrm{PR}^{+}, \mathrm{ER}^{+} / \mathrm{PR}^{-}$, or ER-PR tumors [33, 34]. Thus, PR may have ER-independent functions in breast cancer.

Wang et al. confirmed that the progesterone responsive element in the BCRP promoter is similar to the ERE $[12,35]$, suggesting that the response element might interact with both ER and PR. Reports on the role of PROG in the treatment of breast cancer are controversial. Synthetic progestin regulates transcription differently in normal cells than in breast cancer cells [36]. Although progestin agents appear to stimulate tumor growth under certain conditions [37], one study found that the use of progesterone alone increases breast cancer risk in women [38]. Li et al. demonstrated that nomegestrol acetate reverses multi-drug resistance in MCF-7/ADR cells by down-regulating both mRNA and proteins levels of P-gp and markedly increases intracellular adriamycin accumulation [39]. However, the role of PR in $B C R P$ expression in breast cancer remains unknown.

We have reported that the PROG/PR complex binds to the PRE in the BCRP promoter and regulates BCRP expression in PR-positive breast cancer cells [40]. In the current study, we sought to clarify the molecular mechanisms by which PR regulates BCRP expression. We constructed plasmids containing $B C R P$ cDNA driven by the wild-type PRE promoter (P-BCRP) or a constitutive CMV promoter (C-BCRP). We then established T47D $\left(\mathrm{PR}^{+}\right)$and MDA-MB-231 (PR) cells that stably expressed the two genes and investigated the regulation of PROG on BCRP-mediated drug resistance [41]. We observed that PROG negatively regulated exogenous BCRP gene expression at the transcriptional level in T47D/P-BCRP cells at typical concentrations of circulating hormones. Furthermore, the suppression of PROG was abolished by the addition of RU-486 at a dose equal to a ten-fold molar ratio excess to that of PROG. In T47D/C-BCRP cells, in which BCRP is constitutively expressed, PROG had little 


\section{Cellular Physiology and Biochemistry}

Cell Physiol Biochem 2013;32:344-354

\begin{tabular}{l|l}
\hline DOI: $10.1159 / 000354442$ & (C) 2013 S. Karger AG, Basel
\end{tabular}

www.karger.com/cpb

Wu et al.: Progesterone Regulates BCRP via Progesterone Receptor

effect on $B C R P$ expression. Moreover, in MDA-MB-231 cells expressing either BCRP construct, treatment with PROG induced little change in BCRP mRNA levels. We hypothesize that PROG binds to the PRE in $B C R P$ promoter via PROG-PR complexes and interacts with components of transcriptional mechanism to decrease $B C R P$ gene expression [12]. PROG inhibits $B C R P$ mRNA expression from the gene driven by the endogenous promoter, and this effect can be reversed by RU-486, a specific PROG inhibitor, suggesting that the repression we observed was indeed mediated by PR. When expression was driven by the CMV promoter, however, $B C R P$ mRNA levels were not significantly responsive to PROG and the slight activating effect was not abolished by RU-486. PR might regulate BCRP expression in these cells by interacting with other transcription factors in a PR-PRE-independent manner. In T47D cells that stably express $B C R P$ under the control of the endogenous promoter, flow cytometric analysis showed that PROG suppressed the drug efflux mediated by BCRP and increased the sensitivity of cells to mitoxantrone. Collectively, these results suggest that PROG can reverse BCRP-mediated MDR in $\mathrm{PR}^{+}$breast cancer cells by regulating BCRP expression through PRE.

There are three types of receptor candidates for mediating progesterone actions: membrane progestin receptors (mPRs), progestin receptor membrane components (PGRMCs), and nuclear progestin receptors (nPRs) [42]. In this article, we only addressed classical nPRs and not the rapid activation of intracellular signaling pathways mediated by extra-nuclear PR. Further research will be necessary to clarify the contributions of the three types of receptors in the regulation of BCRP expression. In contrast to our results in T47D cells, Wang et al. reported that PROG up-regulated BCRP expression in BeWo cells [43]. In our study, BCRP expression was driven by the endogenous promoter containing a consensus PRE. In contrast, a Harvey retroviral long terminal repeat promoter drove expression in BeWo cells in the study by Wang et al. Although this difference in promoter may result in the difference in expression observed in the two cell types, the regulation of BCRP expression and function by PROG may occur through different mechanisms in different cells types. For example, further studies are required to explore whether the two PR isoforms, PR-A and PR$\mathrm{B}$, have different functions.

\section{Conflict of Interest}

The experiments comply with the current laws of China and the authors have no conflicts of interest to declare.

\section{Acknowledgements}

This work was supported by the Independent Innovation Foundation of Shandong University (IIFSDU) to X.W. (No. 2012TS117) and the National Natural Science Foundation of China (No. 81272902).

\section{References}

1 Dean M, Hamon Y, Chimini G: The human ATP-binding cassette (ABC) transporter superfamily. J Lipid Res 2001;42:1007-1017.

-2 Kawabata S, Oka M, Soda H, Shiozawa K, Nakatomi K, Tsurutani J, Nakamura Y, Doi S, Kitazaki T, Sugahara K, Yamada Y, Kamihira S, Kohno S: Expression and functional analyses of breast cancer resistance protein in lung cancer. Clin Cancer Res 2003;9:3052-3057.

3 Huss WJ, Gray DR, Greenberg NM, Mohler JL, Smith GJ: Breast cancer resistance protein-mediated efflux of androgen in putative benign and malignant prostate stem cells. Cancer Res 2005;65:6640-6650. 


\section{Cellular Physiology and Biochemistry}

Cell Physiol Biochem 2013;32:344-354

\begin{tabular}{l|l}
\hline DOI: $10.1159 / 000354442$ & (C) 2013 S. Karger AG, Basel
\end{tabular}

www.karger.com/cpb

Wu et al.: Progesterone Regulates BCRP via Progesterone Receptor

-4 Carcaboso AM, Elmeliegy MA, Shen J, Juel SJ, Zhang ZM, Calabrese C, Tracey L, Waters CM, Stewart CF: Tyrosine kinase inhibitor gefitinib enhances topotecan penetration of gliomas. Cancer Res 2010;70:44994508.

5 Doyle LA, Yang W, Abruzzo LV, Krogmann T, Gao Y, Rishi AK, Ross DD: A multidrug resistance transporter from human MCF-7 breast cancer cells. Proc Natl Acad Sci USA 1998;95:15665-15670.

6 Staud F, Pavek P: Breast cancer resistance protein (BCRP/ABCG2). Int J Biochem Cell Biol 2005;37:720725.

7 Volk EL, Farley KM, Wu Y, Li F, Robey RW, Schneider E: Overexpression of wild-type breast cancer resistance protein mediates methotrexate resistance. Cancer Res 2002;62:5035-5040.

8 Yang CH, Schneider E, Kuo ML, Volk EL, Rocchi E, Chen YC: BCRP/MXR/ABCP expression in topotecanresistant human breast carcinoma cells. Biochem Pharmacol 2000;60:831-837.

-9 Lage H, Dietel M: Effect of the breast-cancer resistance protein on atypical multidrug resistance. Lancet Oncol 2000;1:169-175.

10 Kiani J, Khan A, Khawar H, Shuaib F, Pervez S: Estrogen receptor alpha-negative and progesterone receptor-positive breast cancer: lab error or real entity? Pathol Oncol Res 2006;12:223-227.

11 Zhang Y, Zhou G, Wang H, Zhang X, Wei F, Cai Y, Yin D: Transcriptional upregulation of breast cancer resistance protein by 17beta-estradiol in ERalpha-positive MCF-7 breast cancer cells. Oncology 2006;71:446-455.

-12 Wang H, Lee EW, Zhou L, Leung PC, Ross DD, Unadkat JD, Mao Q: Progesterone receptor (PR) isoforms PRA and PRB differentially regulate expression of the breast cancer resistance protein in human placental choriocarcinoma BeWo cells. Mol Pharmacol 2008;73:845-854.

13 Zheng ZY, Bay BH, Aw SE, Lin VC: A novel antiestrogenic mechanism in progesterone receptor-transfected breast cancer cells. J Biol Chem 2005;280:17480-17487.

14 Kumar S, Shelley M, Harrison C, Coles B, Wilt TJ, Mason MD: Neo-adjuvant and adjuvant hormone therapy for localised and locally advanced prostate cancer. Cochrane Database Syst Rev 2006:CD006019.

-15 Tanmahasamut P, Wongwananuruk T: Challenging Regimen for Long-Term Conservative Treatment of Endometrial Adenocarcinoma in Young Women: A Case Report and Review of the Literature. Case Rep Oncol 2010;3:380-385.

16 Rugo HS: The breast cancer continuum in hormone-receptor-positive breast cancer in postmenopausal women: evolving management options focusing on aromatase inhibitors. Ann Oncol 2008;19:16-27.

-17 Li WT, Zhou GY, Song XR, Chi WL, Ren RM, Wang XW: Modulation of BCRP mediated atypical multidrug resistance phenotype by RNA interference. Neoplasma 2005;52:219-224.

18 Wijesuriya HC, Bullock JY, Faull RL, Hladky SB, Barrand MA: ABC efflux transporters in brain vasculature of Alzheimer's subjects. Brain Res 2010;1358:228-238.

19 Sun Y, Zhang T, Gao P, Meng B, Gao Y, Wang X, Zhang J, Wang H, Wu X, Zheng W, Zhou G: Targeting glucosylceramide synthase downregulates expression of the multidrug resistance gene MDR1 and sensitizes breast carcinoma cells to anticancer drugs. Breast Cancer Res Treat 2010;121:591-599.

-20 Sieuwerts AM, Klijn JG, Peters HA, Foekens JA: The MTT tetrazolium salt assay scrutinized: how to use this assay reliably to measure metabolic activity of cell cultures in vitro for the assessment of growth characteristics, IC50-values and cell survival. Eur J Clin Chem Clin Biochem 1995;33:813-823.

-21 Garcia-Escarp M, Martinez-Munoz V, Sales-Pardo I, Barquinero J, Domingo JC, Marin P, Petriz J: Flow cytometry-based approach to ABCG2 function suggests that the transporter differentially handles the influx and efflux of drugs. Cytometry A 2004;62:129-138.

22 Doyle LA, Ross DD: Multidrug resistance mediated by the breast cancer resistance protein BCRP (ABCG2). Oncogene 2003;22:7340-7358.

23 Sarkadi B, Ozvegy-Laczka C, Nemet K, Varadi A: ABCG2 -- a transporter for all seasons. FEBS Lett 2004;567:116-120.

-24 Scheffer GL, Maliepaard M, Pijnenborg AC, van Gastelen MA, de Jong MC, Schroeijers AB, van der Kolk DM, Allen JD, Ross DD, van der Valk P, Dalton WS, Schellens JH, Scheper RJ: Breast cancer resistance protein is localized at the plasma membrane in mitoxantrone- and topotecan-resistant cell lines. Cancer Res 2000;60:2589-2593.

-25 Maliepaard M, Scheffer GL, Faneyte IF, van Gastelen MA, Pijnenborg AC, Schinkel AH, van De Vijver MJ, Scheper RJ, Schellens JH: Subcellular localization and distribution of the breast cancer resistance protein transporter in normal human tissues. Cancer Res 2001;61:3458-3464. 


\section{Cellular Physiology and Biochemistry}

Cell Physiol Biochem 2013;32:344-354

\begin{tabular}{l|l}
\hline DOI: $10.1159 / 000354442$ & (C) 2013 S. Karger AG, Basel
\end{tabular}

Wu et al.: Progesterone Regulates BCRP via Progesterone Receptor

-26 Mao Q Unadkat JD: Role of the breast cancer resistance protein (ABCG2) in drug transport. Aaps J 2005; 7:E118-133.

-27 Yoshikawa M, Ito A, Ishikawa T, Ikegami Y: [Drug resistance mediated by ABC transporters]. Gan To Kagaku Ryoho 2004;31:1-6.

28 Imai Y, Tsukahara S, Ishikawa E, Tsuruo T, Sugimoto Y: Estrone and 17beta-estradiol reverse breast cancer resistance protein-mediated multidrug resistance. Jpn J Cancer Res 2002;93:231-235.

-29 Sugimoto Y, Tsukahara S, Imai Y, Sugimoto Y, Ueda K, Tsuruo T: Reversal of breast cancer resistance protein-mediated drug resistance by estrogen antagonists and agonists. Mol Cancer Ther 2003;2:105-112.

30 Imai Y, Ishikawa E, Asada S, Sugimoto Y: Estrogen-mediated post transcriptional down-regulation of breast cancer resistance protein/ABCG2. Cancer Res 2005;65:596-604.

31 Zhang Y, Wang H, Wei L, Li G, Yu J, Gao Y, Gao P, Zhang X, Wei F, Yin D, Zhou G: Transcriptional modulation of BCRP gene to reverse multidrug resistance by toremifene in breast adenocarcinoma cells. Breast Cancer Res Treat 2010;123:679-689.

-32 Osborne CK: Steroid hormone receptors in breast cancer management. Breast Cancer Res Treat 1998;51:227-238.

-33 Nikolic-Vukosavljevic D, Kanjer K, Neskovic-Konstantinovic Z, Vukotic D: Natural history of estrogen receptor-negative, progesterone receptor-positive breast cancer. Int J Biol Markers 2002;17:196-200.

-34 Keshgegian AA, Cnaan A: Estrogen receptor-negative, progesterone receptor-positive breast carcinoma: poor clinical outcome. Arch Pathol Lab Med 1996;120:970-973.

-35 Ee PL, He X, Ross DD, Beck WT: Modulation of breast cancer resistance protein (BCRP/ABCG2) gene expression using RNA interference. Mol Cancer Ther 2004;3:1577-1583.

-36 Graham JD, Mote PA, Salagame U, van Dijk JH, Balleine RL, Huschtscha LI, Reddel RR, Clarke CL: DNA replication licensing and progenitor numbers are increased by progesterone in normal human breast. Endocrinology 2009;150:3318-3326.

-37 Hofseth LJ, Raafat AM, Osuch JR, Pathak DR, Slomski CA, Haslam SZ: Hormone replacement therapy with estrogen or estrogen plus medroxyprogesterone acetate is associated with increased epithelial proliferation in the normal postmenopausal breast. J Clin Endocrinol Metab 1999;84:4559-4565.

-38 Schairer C, Lubin J, Troisi R, Sturgeon S, Brinton L, Hoover R: Menopausal estrogen and estrogen-progestin replacement therapy and breast cancer risk. Jama 2000;283:485-491.

-39 Li J, Xu LZ, He KL, Guo WJ, Zheng YH, Xia P, Chen Y: Reversal effects of nomegestrol acetate on multidrug resistance in adriamycin-resistant MCF7 breast cancer cell line. Breast Cancer Res 2001;3:253-263.

40 Wu X, Zhang X, Zhang H, Su P, Li W, Li L, Wang Y, Liu W, Gao P, Zhou G: Progesterone receptor downregulates breast cancer resistance protein expression via binding to the progesterone response element in breast cancer. Cancer Sci 2012;103:959-967.

-41 Baglietto L, Severi G, English DR, Krishnan K, Hopper JL, McLean C, Morris HA, Tilley WD, Giles GG: Circulating steroid hormone levels and risk of breast cancer for postmenopausal women. Cancer Epidemiol Biomarkers Prev 2010;19:492-502.

42 Zhu Y, Hanna RN, Schaaf MJ, Spaink HP, Thomas P: Candidates for membrane progestin receptors--past approaches and future challenges. Comp Biochem Physiol C Toxicol Pharmacol 2008;148:381-389.

-43 Wang H, Zhou L, Gupta A, Vethanayagam RR, Zhang Y, Unadkat JD, Mao Q: Regulation of BCRP/ABCG2 expression by progesterone and 17beta-estradiol in human placental BeWo cells. Am J Physiol Endocrinol Metab 2006;290:E798-807. 